\title{
Trends of ectopic pregnancies in Andaman and Nicobar Islands
}

\author{
Anita Yadav ${ }^{1 *}$, Avinash Prakash ${ }^{2}$, Charu Sharma $^{1}$, Bhabani Pegu ${ }^{1}$, Mrinmoy Kumar Saha ${ }^{1}$
}

${ }^{1}$ Department of Obstetrics and Gynecology, Andaman and Nicobar Islands Institute of Medical Sciences, Port Blair, India

${ }^{2}$ Department of Anesthesiology, Andaman and Nicobar Islands Institute of Medical Sciences, Port Blair, India

Received: 30 November 2016

Accepted: 05 December 2016

\section{*Correspondence:}

Dr. Anita Yadav,

E-mail: yadavdr.anita@gmail.com

Copyright: ( $)$ the author(s), publisher and licensee Medip Academy. This is an open-access article distributed under the terms of the Creative Commons Attribution Non-Commercial License, which permits unrestricted non-commercial use, distribution, and reproduction in any medium, provided the original work is properly cited.

\section{ABSTRACT}

Background: Ectopic Pregnancy is a common life threatening emergency in the first trimester of pregnancy. Increase in incidence and impairment in fertility are the major concerns. The present study was undertaken to determine the incidence, clinical presentation, risk factors, diagnosis, management, maternal morbidity and mortality due to ectopic pregnancy in a tertiary care hospital.

Methods: This cross-sectional, descriptive study was done over a period from January 2014 to October 2016. A total of 73 cases were admitted with the diagnosis of ectopic pregnancy. The following parameters: age, parity, risk factors, gestational age, clinical presentation, investigations, findings at surgery, morbidity and mortality associated with ectopic pregnancy was noted.

Results: The incidence of ectopic pregnancy was $0.89 \%$. The peak age of incidence was 25 to 34 years. Multiparous women were the most sufferers. Amenorrhea (93.15\%), abdominal pain $(87.67 \%)$ and vaginal bleeding $(64.38 \%)$ were the frequent presenting complaints. Pelvic inflammatory disease (32.87\%), history of previous caesarean section (26.02\%) and history of abortion (13.69\%) were the important risk factors. There were $90.41 \%$ patients with hemoglobin level less than $10 \mathrm{gm} / \mathrm{dl}, 8.21 \%$ of patients admitted with feature of shock. Majority $(90.41 \%)$ of the cases were diagnosed through history and clinical examination. The commonest site of ectopic pregnancy was the ampulla $(52.94 \%)$. Surgery by open method in the form of salpingectomy $(72.05 \%)$ was the mainstay of treatment. Medical management was possible only in five cases. Morbidity included anemia $(97.05 \%)$, urinary tract infections $(11.76 \%)$ and wound infection $(4.41 \%)$. No maternal mortality noted.

Conclusions: Early presentation, high index of suspicion, early referral and timely intervention in the form of conservative or surgical treatment is the key to successful management of ectopic pregnancy.

Keywords: Awareness, Andaman and Nicobar Islands, Ectopic Pregnancy, Risk factors

\section{INTRODUCTION}

Ectopic pregnancy is a common life threatening emergency in the first trimester of pregnancy. Worldwide, ectopic pregnancy complicates $0.25-2.0 \%$ of all pregnancies. ${ }^{1}$ Overall incidence of ectopic pregnancy is increasing in the past three decades but due to early diagnosis and management, the case fatality rate has come down. Several risk factors have been found to be associated with ectopic pregnancy which includes pelvic inflammatory disease (PID), tubal surgery, use of intrauterine device, multiple sexual partners, previous abdominal surgery and infertility.

Diagnosis can be made with the help of detailed history, examination, urine pregnancy test, quantitative measurement of serum $\beta$ human chorionic gonadotropin $(\beta$-hcg), trans-abdominal as well as trans-vaginal scan, and in doubtful cases, laparoscopy. Early diagnosis reduces the risk of tubal rupture and allows more conservative medical treatment to be employed. 
Ectopic pregnancy is a major health problem among women of reproductive age group. It not only threatens the life if not treated timely and effectively, but also compromises the future fertility of the women. The aim of the present study was to determine the incidence, clinical presentation, risk factors, diagnosis, management, maternal morbidity and mortality due to ectopic pregnancy in a tertiary care hospital.

\section{METHODS}

This study was conducted in the Department of Obstetrics and Gynecology, Andaman and Nicobar Islands Institute of Medical Sciences, Port Blair, India, the only tertiary referral hospital situated in the heart of Port Blair. This study was conducted over a period from January 2014 to October 2016. Ethical approval was taken from the Institutional Ethics Committee. A total of 73 cases reported during this time frame with ectopic pregnancy were included in this study. The case records of the patients were traced from medical records department and operation theatre registers. Information regarding total number of deliveries during study period, details of demographic characteristics, presenting clinical symptoms and signs, detailed obstetric history, parity, gestational age at presentation, use of contraception, risk factors for ectopic pregnancy, diagnostic tool used, treatment modalities (whether surgical or medical), intraoperative findings and outcomes of ectopic pregnancy were recorded. Data were collected, tabulated and analysed.

\section{RESULTS}

Table 1: Distribution of cases according to age and parity.

\begin{tabular}{|lll|}
\hline Characteristics & Number of cases & $\%$ \\
\hline Age (Years) & & \\
\hline$<20$ & 3 & 4.10 \\
\hline $20-24$ & 11 & 15.06 \\
\hline $25-29$ & 26 & 35.61 \\
\hline $30-34$ & 23 & 31.50 \\
\hline$\geq 35$ & 10 & 13.69 \\
\hline Parity & & \\
\hline 0 & 11 & 15.06 \\
\hline 1 & 14 & 19.17 \\
\hline 2 & 26 & 35.61 \\
\hline$\geq 3$ & 22 & 30.13 \\
\hline
\end{tabular}

During the study period, there were a total of 8140 deliveries and 73 cases of ectopic pregnancy were admitted in the hospital. The incidence of ectopic pregnancy in the present study was $0.89 \% \quad(73 / 8140$ deliveries).

The mean age of the patients was $29.15 \pm 5.10$ years. Majority $(67.11 \%, 49 / 73)$ of the patients were in the age group of 25 to 34 years. Multiparous women were found to be more prone to have ectopic pregnancy $(65.75 \%$, 48/73) as depicted in Table 1.

Table 2: Distribution of cases according to clinical presentation.

\begin{tabular}{|lll|}
\hline Symptom at presentation & Number (N) & $\%$ \\
\hline Amenorrhea & 68 & 93.15 \\
\hline Pain abdomen & 64 & 87.67 \\
\hline Bleeding per vagina & 47 & 64.38 \\
\hline Shock & 06 & 8.21 \\
\hline
\end{tabular}

The most common presenting clinical symptoms were amenorrhea, abdominal pain and vaginal bleeding $(93.15 \%, 87.67 \%$ and $64.38 \%$ respectively) as shown in Table 2. Most $(93.15 \%, 68 / 73)$ of cases had history of amenorrhea ranging from 5 to 8 weeks and rest of $6.84 \%$ $(5 / 73)$ cases had no history of amenorrhea. Around $8.21 \%$ $(6 / 73)$ of the patients were presented in a state of shock. Almost all patients $90.41 \%(66 / 73)$ were anemic with hemoglobin level less than $10 \mathrm{~g} / \mathrm{dl}$ (Figure 1).

Table 3: Distribution of cases according to risk factors.

\begin{tabular}{|lll|}
\hline Risk factor & Number $(\mathbf{N})$ & $\%$ \\
\hline $\begin{array}{l}\text { Pelvic inflammatory } \\
\text { diseases }\end{array}$ & 24 & 32.87 \\
\hline $\begin{array}{l}\text { Lower segment caesarean } \\
\text { section }\end{array}$ & 19 & 26.02 \\
\hline Previous abortion & 10 & 13.69 \\
\hline Tubal surgery & 08 & 10.95 \\
\hline $\begin{array}{l}\text { Intrauterine contraceptive } \\
\text { device }\end{array}$ & 05 & 6.84 \\
\hline Previous ectopic pregnancy & 04 & 5.47 \\
\hline Infertility & 02 & 2.73 \\
\hline Bicornuate uterus & 01 & 1.36 \\
\hline
\end{tabular}

Table 4: Distribution of cases according to site of ectopic pregnancy $(\mathrm{N}=68)$.

\begin{tabular}{|lll|}
\hline Site & Number & $\%$ \\
\hline Ampulla & 36 & 52.94 \\
\hline Isthmus & 12 & 17.64 \\
\hline Cornua & 10 & 14.70 \\
\hline Tubal abortion & 06 & 8.82 \\
\hline Ovary & 03 & 4.41 \\
\hline Rudimentary Horn & 01 & 1.47 \\
\hline
\end{tabular}

Table 3 presents at a glance the major risk factors among the study participants. The majority $(32.87 \%)$ of the patients had previous history of pelvic inflammatory disease. Out of the eight patients who underwent sterilization, three had post-partum sterilization and five had laparoscopic sterilization. None of the patients had concurrent sterilization with caesarean section. Four out of the seventy three patients had previous ectopic pregnancy hence the recurrence rate was $5.47 \%$. 
Table 5: Distribution of cases according to surgery $(\mathrm{N}$ $=68$ ).

\begin{tabular}{|lll|}
\hline Surgery & Number & Percentage \\
\hline Milking of tube & 06 & 8.82 \\
\hline Salpingostomy & 04 & 5.88 \\
\hline $\begin{array}{l}\text { Total unilateral } \\
\text { Salpingectomy }\end{array}$ & 48 & 70.58 \\
\hline $\begin{array}{l}\text { Bilateral } \\
\text { Salpingectomy }\end{array}$ & 02 & 2.94 \\
\hline Salpingoopherectomy & 08 & 11.76 \\
\hline
\end{tabular}

Majority $(90.41 \%, 66 / 73)$ of the cases were diagnosed through history taking and clinical physical examination. The urinary pregnancy test was positive in $84.93 \%$ $(62 / 73)$ of the cases. Ultrasound revealed ectopic pregnancy in $60.27 \%$ (44/73) cases.

\section{Hemoglobin}
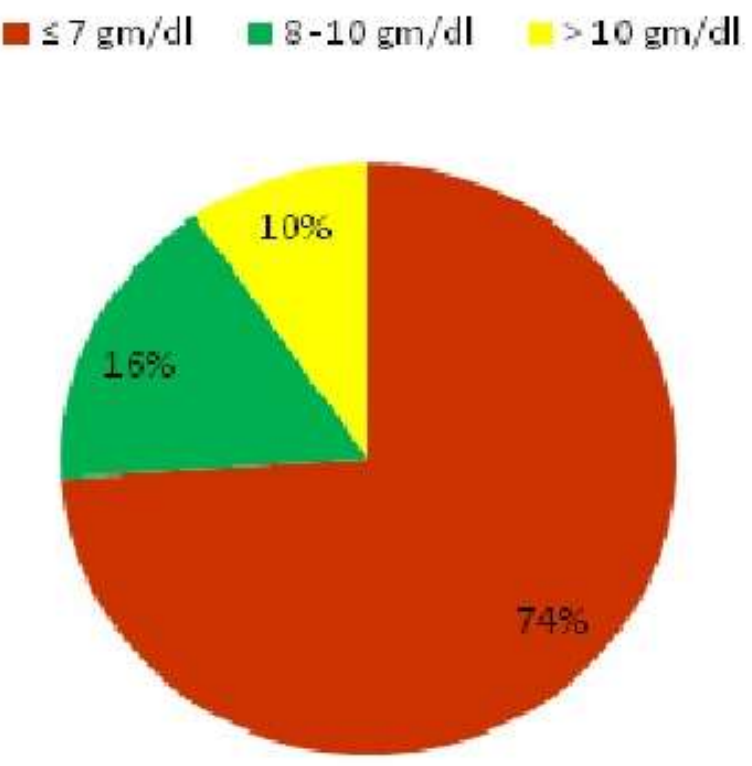

Figure 1: Distribution of cases according to haemoglobin level.

Majority $(93.15 \%, 68 / 73)$ of patients underwent surgical management by laparoscopy/ laparotomy depending on the condition of the patient. All the cases that were diagnosed clinically had immediate laparotomy performed on them. On laparotomy, ruptured ectopic pregnancy was found in $84.93 \%(62 / 73)$ of cases and $15.06 \%$ (11/73) cases had unruptured ectopic pregnancy. Right sided tubal pregnancy was present in $69.56 \%$ (48/69) cases and left tubal involvement in $36.23 \%$ $(25 / 69)$. The commonest site of ectopic pregnancy was the ampulla $(52.94 \%, 36 / 68)$ region of the fallopian tube, while the ovarian site had the lowest $(4.41 \%, 3 / 68)$ occurrence (Table 4).
Table 5 detailed the type of surgical procedure performed on the patients. The commonest $(72.05 \%, 49 / 68)$ surgical modality of treatment was unilateral salpingectomy. Five patients underwent medical management with injection methotrexate, out of which two were given single dose and three were given multiple doses of injection methotrexate respectively.

The most common post-operative complications in the present study were anemia $(97.05 \%, 66 / 68)$, urinary tract infections $(11.76 \%, 8 / 68)$ and wound infection $(4.41 \%$, $3 / 68)$. Majority $73.97 \%$ (54/73) of patients received more than two units of blood. There was no maternal mortality due to ectopic pregnancy in the present study.

\section{DISCUSSION}

Ectopic pregnancy may be the only life- threatening emergency in which prevalence has increased as mortality has declined. This was due to technological advances that allow the diagnosis of pregnancy before menses are missed, combined with a heightened awareness and aggressiveness on the physician's part in acting on increased suspicion. Any reproductive age group women presenting with acute pain abdomen, ectopic pregnancy should be excluded.

This Study establishes the fact that the incidence of ectopic pregnancy is on the increase. In our study the incidence of ectopic pregnancy was found to be $0.89 \%$ of deliveries which is comparable to other studies. ${ }^{2,3,4,5}$

In this Study, the highest frequency of ectopic pregnancy was recorded among age group of 25 to 34 years, similar results were found in different studies. ${ }^{6,7}$ The reason for high mean age is that in recent years, the age at first conception has increased, which ultimately contribute to the increased incidence rate.

The highest incidence of ectopic pregnancy was noted among multiparous women which is close to other studies. ${ }^{3,6,8}$ Majhi AK et al showed increased risk of ectopic pregnancy in primigravida which is conflicting with the result of present study. ${ }^{9}$

The clinical presentation ranges from non - specific lower abdominal pain to shock. Amenorrhea followed by lower abdominal pain was the commonest clinical presentation in the present study, which is in comparison with the study by Prasanna et al, where $96 \%$ of the patients had history of amenorrhea, $90 \%$ had pain abdomen and $68 \%$ had bleeding per vaginum. ${ }^{3}$ In the present study, $8.21 \%$ of patients presented with features of shock which is almost similar to the Study by Majhi AK et al $(9.4 \%){ }^{9}$

Pelvic inflammatory disease (PID), abdominal surgeries including caesarean section and history of previous abortion were common identified risk factors for ectopic pregnancy. Pelvic inflammatory disease was the 
commonest risk factor identified in $32.87 \%$ women. This frequency is almost consistent with the study of Yamasaki IA et al $(31.68 \%) .{ }^{10}$ The trend of early marriages in our society coupled with lack of knowledge regarding sexual health predisposes the young women to sexually transmitted infections. The alarming risk of PID need a preventive strategy with promotion of health education, in particular the safe sexual practice in our community. Emphasis should be towards treatment of both partners for complete cure. History of previous ectopic pregnancy was found in $5.47 \%$ of cases which was also noticed in the study done by Mufti $\mathrm{S}$ et al where, $5.26 \%$ of patients gave history of previous ectopic pregnancy. ${ }^{11}$ It reflects the underlying tubal pathology which is almost always bilateral.

There have been major advances in the diagnosis and management of ectopic pregnancy during the last 20 years. Early diagnosis of ectopic pregnancy helps to reduce the rate of female morbidity and mortality. As the risk factors do not necessary help in establishing a prompt diagnosis, screening of a female patient in her reproductive years who presents with history of amenorrhea, abdominal pain and vaginal bleeding for ectopic pregnancy will help for the same. The urine pregnancy test, serum $\beta$ human chorionic gonadotropin $(\beta-h c g)$ and ultrasound were the diagnostic tools used for diagnosis of ectopic pregnancy. Studies have shown that ultrasonography should be the initial investigation for symptomatic women in their first trimester; when the results are indeterminate, the serum $\beta$-hcg concentration should be measured. Serial measurement of $\beta$-hcg and progesterone concentrations may be useful when the diagnosis remains unclear.

In present study, commonest site for ectopic pregnancy was tubal $(94.11 \%)$, which is same as in study by Panchal $\mathrm{D}$ et al $(98.33 \%) .{ }^{12}$ Among tubal pregnancies, $84.93 \%$ were ruptured and $15.06 \%$ were unruptured. Around $8.82 \%$ were tubal abortion. The high rate of ruptured ectopic pregnancies found in this study shows that most people living in these Islands are yet to change their poor health - seeking behavior in terms of accessing medical care early so that prompt diagnosis and treatment can be administered.

Most of the cases $(93.15 \%)$ of ectopic pregnancy were in the gestation age of 5 to 8 weeks. This may be due to more number of ampullary (52.94\%) tubal pregnancies which usually ruptures around 8 weeks.

Ectopic pregnancy can be treated both medically as well as surgically depending on the clinical condition of the patient, site of ectopic and availability of resources. The two main aim of treatment is to preserve maternal life and to retain her reproductive capacity. Laparoscopic and medical therapy have now emerged as widely used therapeutic modalities with great success in terms of reduced morbidity, shorter hospital stay and conservation of fertility. Since most of our patients presented late in a critical state they could not be offered these modern management options. In present study, majority (93.15\%) of patients underwent surgery either laparoscopy $(5 / 68)$ / laparotomy (63/68) depending on the clinical condition of the patient. The most common surgeries performed were total unilateral salpingectomy (70.58\%), Salpingooophorectomy $(11.76 \%)$ and salpingostomy (5.88\%). Similar findings were also noted in different studies. ${ }^{6,9,11}$

Morbidity included anemia, urinary tract infections and wound infection. Anemia, which was the commonest (97.05\%) complication in this study, was due to excessive blood loss from the ruptured site and most of these patients with ruptured ectopic pregnancy present very late to hospital.

By reducing and identifying the risk factors and detecting the patients at the earliest it is possible to improve the prognosis so far as morbidity, mortality and fertility are concerned. There was no maternal mortality due to ectopic pregnancy in the present study. This may be as a result of prompt and proper management of the patients.

\section{CONCLUSION}

In conclusion, ectopic pregnancy still remains a gynaecological catastrophe in developing country like India and a major challenge to the reproductive performance of women worldwide. The study has shown that the frequency of occurrence of ectopic pregnancy is on the increase. It can be reduced with measure designed to curtail the high incidence of pelvic inflammatory disease and post abortal sepsis which include health education on safer sex and provision of family planning services, such as condoms and other barrier contraceptives. With its rising incidence, it is necessary to devise means of early detection and treatment. This emphasizes the importance of a thorough clinical evaluation and appropriate investigations to patients with high suspicious so that patients can be benefited by the use of recent therapeutic modalities with avoidance of open surgery and better fertility conservation. Early presentation, high index of suspicion, early referral and timely intervention in the form of conservative or surgical treatment is the key to successful management.

\section{Funding: No funding sources \\ Conflict of interest: None declared}

Ethical approval: The study was approved by the Institutional Ethics Committee

\section{REFERENCES}

1. Thonneau P, Hijazi Y, Goyaux N, Calvez T, Keita N. Ectopic pregnancy in Conakry, Guinea. Bull World Health Organ. 2002;80:365-70.

2. Wakankar R, Kedar K. Ectopic Pregnancy- A rising Trend. Int J Sci Stud. 2015;3(5):18-22.

3. Prasanna B, Jhansi CB, Swathi K, Shaik MV. A study on risk factors and clinical presentation of 
ectopic pregnancy in women attending a tertiary care centre. IAIM. 2016;3(1):90-6.

4. Gaddagi RA, Chandrashekhar AP. A Clinical Study of Ectopic Pregnancy. J Clin Diagn Res. 2012;6(5):867-9.

5. Tuli AG, Goyal S, Livingston D, Kurian AS. Ectopic pregnancy: a five year retrospective study in a tertiary care hospital. Int J Reprod Contracept Obstet Gynecol. 2015;4(5):1400-3.

6. Igwegbe AO, Eleje GU, Okpola BC. An appraisal of the management of ectopic pregnancy in a Nigerian Tertiary Hospital. Ann Med Health Science Res. 2013;3(2):166-70.

7. Onwuhafua PI, Onwuhafua A, Adesiyun GA, Adze J. Ectopic pregnancies at Ahmadu Bello University Teaching Hospital, Kaduna Northern Nigeria. Trop J Obstet Gynaecol. 2001;18:82-6.

8. Shetty S, Shetty A. A clinical Study of Ectopic Pregnancies in a Tertiary care hospital of Mangalore, India. Innovative Journal of Medical and Health Science. 2014;4(1):305-9.
9. Majhi AK, Roy N, Karmakar KS, Banerjee PK. Ectopic pregnancy - An analysis of 180 cases. J Indian Med Assoc. 2007;105(6):308-12.

10. Yakasai IA, Abdullahi J, Abubakar IS. Management of ectopic pregnancy in Aminu Kano teaching hospital Kano Nigeria: A 3 year. Global Advanced Research Journal of Medicine and Medical Sciences. 2012;1(7):181-5.

11. Mufti S, Rather S, Mufti S, Rangrez RA, Wasiqa, Khalida. Ectopic pregnancy: an analysis of 114 cases. JK Practitioner. 2012;17(4):20-3.

12. Panchal D, Vaishnav G, Solanki K. Study of Management in Patient with Ectopic Pregnancy. NJIRM. 2011;2(3):91-4.

Cite this article as: Yadav A, Prakash A, Sharma C, Pegu B, Saha MK. Trends of ectopic pregnancies in Andaman and Nicobar Islands. Int J Reprod Contracept Obstet Gynecol 2017;6:15-9. 